\title{
CYP2C19 variant mitigates Alzheimer disease pathophysiology in vivo and postmortem
}

Andréa L. Benedet, MSc, Lei Yu, PhD, Aurélie Labbe, PhD, Sulantha Mathotaarachchi, MSc, Tharick A. Pascoal, MD, Monica Shin, MSc, Min-Su Kang, BSc, Serge Gauthier, MD, Guy A. Rouleau, MD, PhD, Judes Poirier, PhD, David A. Bennett, MD, and Pedro Rosa-Neto, MD, PhD, for the Alzheimer's Disease Neuroimaging Initiative

Neurol Genet 2018;4:e216. doi:10.1212/NXG.0000000000000216

\section{Abstract}

\section{Objective}

To verify whether CYP polymorphisms are associated with amyloid- $\beta(A \beta)$ pathology across the spectrum of clinical Alzheimer disease using in vivo and postmortem data from 2 independent cohorts.

\section{Methods}

A candidate-gene approach tested the association between 5 genes $(28$ single nucleotide polymorphisms) and $\mathrm{A} \beta$ load measured in vivo by the global $\left[{ }^{18} \mathrm{~F}\right]$ florbetapir PET standardized uptake value ratio (SUVR) in 338 Alzheimer's Disease Neuroimaging Initiative participants. Significant results were then tested using plasma $A \beta$ and CSF $A \beta$ and $A \beta /$ phosphorylated tau $(\mathrm{A} \beta / \mathrm{p}$-tau $)$ ratio in the same cohort. The significant association was also generalized to postmortem $A \beta$ load measurement in the Rush Religious Orders Study/Memory and Aging Project cohorts. In addition, global cognition was used as a phenotype in the analysis in both cohorts.

\section{Results}

Analysis of A $\beta$ PET identified a variant in the CYP2C19 gene (rs4388808; $p=0.0006$ ), in which carriers of the minor allele (MA) had a lower global SUVR. A voxel-wise analysis revealed that the variant is associated with a lower $A \beta$ load in the frontal, inferior temporal, and posterior cingulate cortices. MA carriers also had higher CSF $\mathrm{A} \beta(p=0.003)$ and $\mathrm{A} \beta / \mathrm{p}$-tau ratio $(p=$ 0.02 ) but had no association with $A \beta$ plasma levels. In postmortem brains, MA carriers had a lower A $\beta$ load $(p=0.03)$. Global cognition was higher in MA carriers, which was found to be mediated by $\mathrm{A} \beta$.

\section{Conclusions}

Together, these findings point to an association between CYP2C19 polymorphism and A $\beta$ pathology, suggesting a protective effect of the MA of rs4388808. Despite the several possibilities in which CYP2C19 affects brain A $\beta$, the biological mechanism by which this genetic variation may act as a protective factor merits further investigation.

\footnotetext{
From the Translational Neuroimaging Laboratory (A.L.B., S.M., T.A.P., M.S., M.-S.K., P.R.-N.), and Alzheimer's Disease Research Unit (S.G., P.R.-N.), McGill University Research Centre for Studies in Aging, Montreal, Canada; CAPES Foundation (A.L.B.), Ministry of Education of Brazil, Brasília, Brazil; Rush Alzheimer's Disease Center (L.Y., D.A.B.), Rush University Medical Center, Chicago, IL; Department of Decision Sciences (A.L.), HEC Montreal, Montreal, Canada; Department of Epidemiology (A.L.), Biostatistics \& Occupational Health, McGill University, Montreal, Canada; Department of Neurology and Neurosurgery (G.A.R., J.P., P.R.-N.), Douglas Hospital Research Centre (J.P., P.R.-N.), and Department of Psychiatry (J.P.), McGill University, Montreal, Canada; and Montreal Neurological Institute (G.A.R., P.R.-N.), Canada.

Coinvestigators are listed at http://links.Iww.com/NXG/A21.
}

Funding information and disclosures are provided at the end of the article. Full disclosure form information provided by the authors is available with the full text of this article at Neurology.org/NG

The Article Processing Charge was funded by the authors.

This is an open access article distributed under the terms of the Creative Commons Attribution-NonCommercial-NoDerivatives License 4.0 (CC BY-NC-ND), which permits downloading and sharing the work provided it is properly cited. The work cannot be changed in any way or used commercially without permission from the journal. 


\section{Glossary}

$\mathbf{A A}=$ arachidonic acid $\mathbf{A} \boldsymbol{\beta}=$ amyloid $-\beta ; \mathbf{A D}=$ Alzheimer disease $;$ ADNI $=\mathrm{AD}$ Neuroimaging Initiative $; \mathbf{A P P}=$ amyloid precursor protein; $\mathbf{C D R}=$ clinical dementia rating; $\mathbf{C N}=$ cognitively normal; $\mathbf{C Y P}=$ cytochrome P450; EET = epoxyeicosatrienoic acid; $\mathbf{L D}=$ linkage disequilibrium; $\mathbf{M A}=$ minor allele; $\mathbf{M A F}=$ minor allele frequency; $\mathbf{M A P}=\mathrm{Memory}$ and Aging Project; $\mathbf{M C I}=$ mild cognitive impairment; $\mathbf{M M S E}=$ Mini-Mental State Examination; PHF = paired helical filament; $\mathbf{p}-$ tau = phosphorylated tau; ROS = Religious Orders Study; SNP = single nucleotide polymorphism; SUVR = standardized uptake value ratio.

In sporadic Alzheimer disease $(\mathrm{AD})$, accumulation of amyloid- $\beta(A \beta)$ seems to be associated with reduced $A \beta$ clearance, but little is known about the biochemical pathways underlying cerebral $\mathrm{A} \beta$ metabolism.

Cytochrome P450 (CYP) is a family of enzymes known to metabolize several endogenous and exogenous substrates. Besides metabolizing drugs, brain CYPs are also involved in the modulation of blood flow, metabolism of fatty acids, cholesterol, and neurotransmitters, and mobilization of intracellular calcium, ${ }^{1-3}$ all pathways that have been somehow linked to $\mathrm{AD}$ and/or amyloid metabolism. In addition, studies have shown that CYP proteins and their genetic variants are associated with the brain immune response ${ }^{2}$ and neurodegenerative diseases. ${ }^{2,4,5}$

Although previous evidence shows CYP expression in areas affected by $\mathrm{AD}$ such as the amygdala, frontal and temporal cortices, and the hippocampus, ${ }^{6,7}$ there are only a few reports documenting a link between CYPs and $\mathrm{AD}$ pathophysiology. In one study, the overexpression of human amyloid precursor protein (APP) on the Tg2576 mice model was associated with elevated CYP hepatic function, while their renal counterparts were depressed. ${ }^{8}$ In addition, another study presented evidence that $A \beta$ stimulates $\mathrm{NADPH}$ cytochrome P450 reductase (POR), a CYP inducer, in APP transgenic mice and human $\mathrm{AD}$ brains, which may affect the redox status. ${ }^{9}$

In line with the evidence that $A \beta$ can stimulate metabolic cascades in a similar fashion as foreign compounds, ${ }^{9,10}$ and knowing that brain CYP could potentially affect amyloid metabolism also through other mechanisms, we tested the hypothesis that variants in CYP genes could be associated with $A \beta$ and, consequently, have an impact in cognitive performance. We examined the association of CYP variants with biomarkers of $A \beta$ load in vivo and postmortem, as further specified.

\section{Methods}

\section{Study participants}

Discovery analysis data were obtained from the $\mathrm{AD}$ Neuroimaging Initiative (ADNI) database (adni.loni.usc.edu). For this study, cognitively normal $(\mathrm{CN})$ individuals had a Mini-Mental State examination (MMSE) score of 24 or higher and a clinical dementia rating (CDR) of 0 . The operational criteria adopted for mild cognitive impairment (MCI) were participants who had an MMSE score equal to or greater than 24 , a CDR of 0.5 , subjective memory concern, objective memory loss measured by educationadjusted scores on delayed recall of 1 paragraph from Wechsler Memory Scale Logical Memory II ( $\geq 16$ years: $\leq 8$; $8-15$ years: $\leq 4$; and $0-7$ years: $\leq 2$ ), and essentially normal activities of daily living. Participants with $\mathrm{AD}$ were individuals with an MMSE score lower or equal to 26, CDR higher than 0.5 , who met the National Institute of Neurological and Communicative Disorders and Stroke-Alzheimer's Disease and Related Disorders Association criteria for probable AD. All individuals had absence of any other neuropsychiatric disorders. The ADNI inclusion/exclusion criteria are described in detail at adni-info.org.

Our report also used data from the Religious Orders Study (ROS) and Rush Memory and Aging Project (MAP), 2 longitudinal clinical pathologic cohort studies of aging and dementia. ${ }^{11,12}$ All participants enrolled without known dementia and agreed to annual clinical and neuropsychological assessments and brain donations after death. The clinical diagnosis of dementia and $\mathrm{AD}$ followed the National Institute of Neurological and Communicative Disorders and Stroke-Alzheimer's Disease and Related Disorders Association recommendations. The MCI diagnosis is given to participants who were rated as impaired based on MMSE and on the Consortium to Establish a Registry for Alzheimer's Disease (CERAD) neuropsychological measures but who were not found to have dementia by the examining neurologist. Our study includes only MCI participants with 1 impaired domain and no other cause of cognitive impairment. Notably, the studies are conducted by the same team of investigators and share a large common core of testing batteries, which allow for combined analyses.

The discovery sample consisted of a subset of ADNI participants who had $\left[{ }^{18} \mathrm{~F}\right]$ florbetapir PET, genetic data, and CSF data available. The findings obtained with the discovery sample were then generalized to the Rush-ROS/MAP participants who died at age 90 years or younger.

\section{Standard protocol approvals, registrations, and patient consents}

This secondary analysis study followed all institutional review board regulations, which are detailed in the supplementary methods. 


\section{Phenotypes}

From the ADNI, we obtained demographics, neurocognitive scores, CSF, and plasmatic data available after passing rigorous quality control. The preprocessed imaging and genetic data underwent additional processing and quality control before the statistical analysis in our study as described below. From Rush, all the data used in this project to perform statistical analyses were already processed and quality controlled with very rigorous criteria.

In the $\mathrm{ADNI}$ cohort, the brain $\mathrm{A} \beta$ load was estimated using the $\left[{ }^{18} \mathrm{~F}\right]$ florbetapir PET standardized uptake value ratio (SUVR, details are provided in figure 1 and e-methods). Separately, $A \beta$ and hyperphosphorylated tau ( $p$-tau) levels were measured in the CSF and plasma. These data were obtained by the Biomarkers Consortium CSF, and the description of the methodology regarding the sample acquisition, processing, and analysis is available at the ADNI website (adni.loni.usc.edu/data-samples/biospecimen-data/).

In the Rush-ROS/MAP cohort, postmortem data of the $A \beta$ load and paired helical filament (PHF) tau tangle density were obtained from 8 brain regions using immunohistochemistry. ${ }^{13}$
Cognitive function was evaluated in both the ADNI and RushROS/MAP. For the ADNI, the global cognition scores were developed by making a z-score of the sum of the memory and the executive function composite scores. In the Rush-ROS/ MAP, the global cognitive scores were based on 17 cognitive performance tests, and we included only participants who underwent autopsies; thus, the last valid cognitive score proximate to death was used for this analysis (for further details, see e-Methods, http://links.lww.com/NXG/A20).

We used gene expression data to examine cis expression quantitative trait loci (eQTL). For the ADNI, total RNA was obtained from the peripheral blood-at the same visit when the imaging data were obtained — and, after quality control, was hybridized to the Affymetrix Human Genome U219 array plate as described. ${ }^{14}$ The normalized and quality-controlled expression data ${ }^{14}$ were used. For the Rush-ROS/MAP, RNA was extracted from the gray matter of dorsolateral prefrontal cortex blocks using the miRNeasy Mini Kit (Qiagen, Venlo, Netherlands) and the RNase-free DNase Set (Qiagen). These samples were quantified and qualified as described ${ }^{15}$ and then sequenced on the Illumina HiSeq with $101 \mathrm{bp}$ paired-end reads. The normalized and quality-controlled expression data were used. In both analyses, the RNA integrity measurement was used as a covariate.

Figure $1\left[{ }^{18} \mathrm{~F}\right]$ florbetapir standardized uptake value ratio analytical method

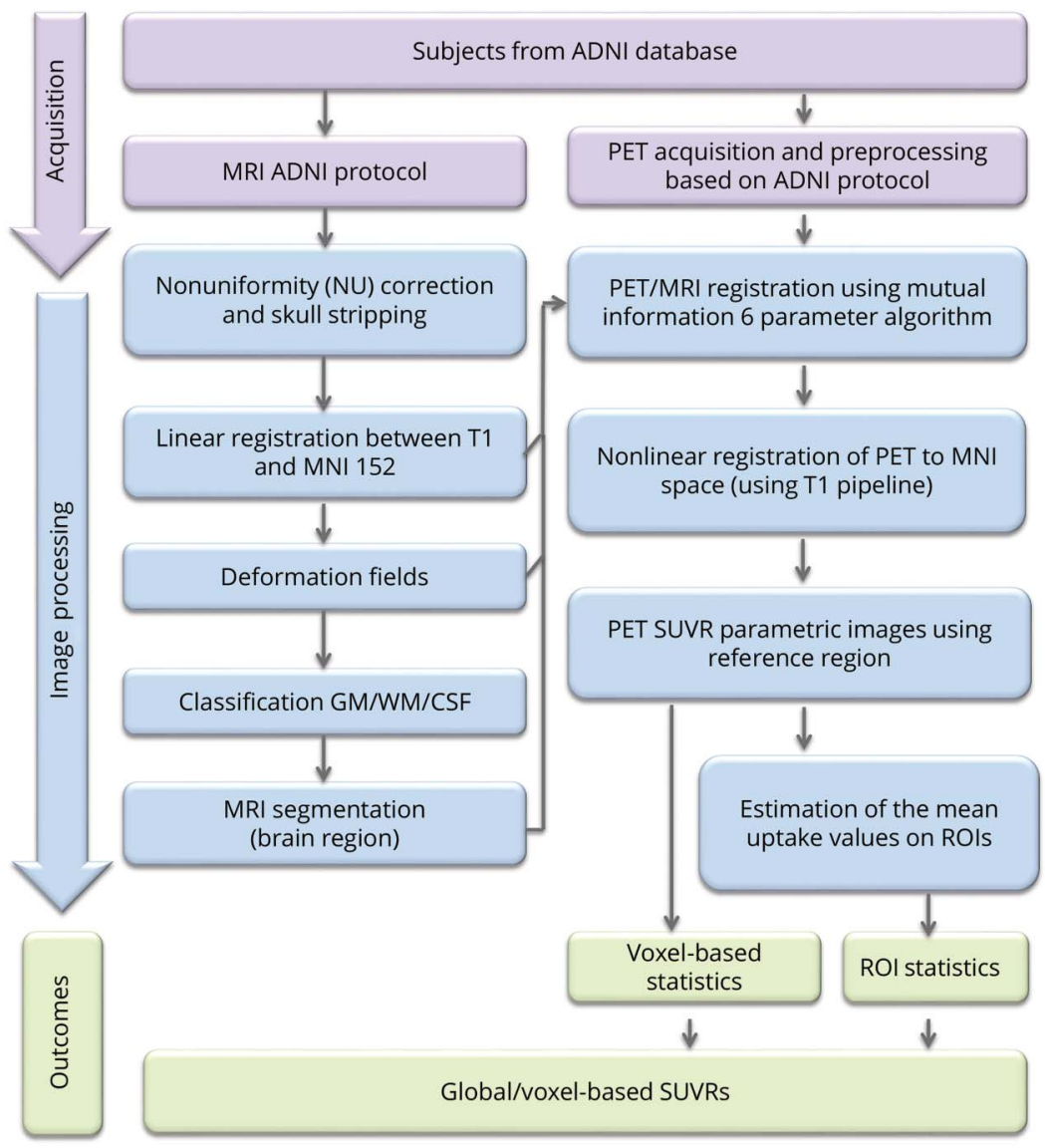

Flowchart showing acquisition methods (purple), image processing (blue), and outcomes (green). ADNI = Alzheimer's Disease Neuroimaging Initiative; GM = gray matter; ROI = region of interest; SUVR = standardized uptake value ratio; $\mathrm{WM}=$ white matter. 
Genotyping, imputation, and gene selection We interrogated single nucleotide polymorphisms (SNPs) from the CYP genes of the 5-probably-most important metabolizers: CYP3A4, CYP2D6, CYP2C9, CYP1A2, and CYP2C19. ${ }^{3,16-18}$ Methods involved in DNA processing are detailed in the supplementary methods section (http://links. lww.com/NXG/A20). Using PLINK, ${ }^{19}$ the SNPs within these genes were recoded based on the dominant model with respect to the MAs, and the ones in high linkage disequilibrium (LD) $\left(r^{2}>0.8\right)$ were removed from the analysis to avoid unnecessary testing. A total of 28 SNPs were used in the initial step of the association analysis.

For Rush-ROS/MAP cohorts, DNA was extracted, genotyped, imputed, and quality controlled according to the procedures described in e-Methods (http://links.lww.com/NXG/A20).

\section{Statistical analysis}

The statistical tests were performed in R statistical software, ${ }^{20}$ where linear regression models were used to test the association between the genotypes and the phenotypes in both cohorts, separately. All statistical models included the covariates of age, sex, and APOE- 44 carriage status, except for the models in which global cognition was the outcome measure, where the APOE- $\varepsilon 4$ status was replaced by years of education. The initial analysis-using the global $\left[{ }^{18} \mathrm{~F}\right]$ florbetapir SUVR as a phenotype-was performed to interrogate a total of $28 \mathrm{SNPs}$ (table e-1, http://links.lww.com/NXG/A19). To correct for multiple testing, the statistical significance of the SNP discovery was set at $p<0.0017$ using a Bonferroni correction for 28 tests and a type I error $\alpha=0.05$. The significant SNPs were further tested for associations with other phenotypes in ADNI and Rush-ROS/MAP cohorts. To test for group differences in the diagnostic status, we added diagnosis as a covariate in the regression models and also tested the interaction between the diagnostic status and desired independent variable. Effect size calculations (Cohen $d$ ) were also used.

A voxel-based analysis was performed using the RMINC imaging tool, ${ }^{21}$ where parametric images were obtained contrasting the $\left[{ }^{18} \mathrm{~F}\right]$ florbetapir SUVR between the genotype groups of the SNP found in the discovery analysis. After random field theory correction for multiple comparisons, the $t$ value threshold of significance was $\leq-3.1(p \leq 0.001)$.

Mediation analysis was used to examine whether the SNP associations with cognition were mediated through the effect of $A \beta$. To test this hypothesis, first, the association of CYP SNPs with global cognitive performance was evaluated using linear regression models. Then, if the association was significant, the measure of $A \beta$ was added to this model to check whether the SNP associations with cognition were attenuated because of $A \beta$.

\section{Results}

Demographics and general information of the ADNI and Rush-ROS/MAP cohorts are presented in table 1. After imaging and genetic quality control, a total of 338 ADNI participants were studied, including $186 \mathrm{CN}, 105$ single- or multiple-domain amnestic $\mathrm{MCI}$, and $47 \mathrm{AD}$. A total of 738 Rush-ROS/MAP participants were analyzed, including 301 $\mathrm{CN}, 179$ amnestic MCI, and $258 \mathrm{AD}$. As expected, in both cohorts, $\mathrm{CN}$ individuals had higher MMSE scores and fewer were $A P O E-\varepsilon 4$ carriers as compared to both $\mathrm{MCI}$ and $\mathrm{AD}$. There was no difference in sex or years of formal education between diagnostic groups in both cohorts (details are provided in table e-2, http://links.lww.com/NXG/A19).

\section{CYP2C19 polymorphism is associated with the global $\left[^{18} \mathrm{~F}\right]$ florbetapir SUVR in the ADNI cohort} The discovery analysis tested the association of 28 SNPs from CYP genes with the global $\left[{ }^{18} \mathrm{~F}\right]$ florbetapir SUVR. The analysis unveiled an association of an SNP (rs4388808) in the CYP2C19 gene $(t=-3.43 ; p=0.0006)$ (figure $2 \mathrm{~A})$. The minor allele frequency (MAF) of $\mathrm{rs} 4388808^{\mathrm{G}}$ in the ADNI cohort was 0.19 , and the minor allele (MA) carriers displayed less $\left[{ }^{18} \mathrm{~F}\right]$ florbetapir binding as compared to the noncarriers. It is important that the association remained significant when adjusting the model for diagnosis. In addition, no interaction was found between the SNP and diagnostic status. The estimated effect size of rs4388808 in the whole sample was Cohen $d=0.36$. Of interest, the effect size was greater for the subset of $A P O E-\varepsilon 4$ carriers (Cohen $d=0.51$ ) as compared to $A P O E-\varepsilon 4$ noncarriers (Cohen $d=0.33$ ).

\section{MA carriers of the CYP2C19 polymorphism have less $A \beta$ in $A D$-related regions in the ADNI cohort}

To identify the brain areas responsible for the global difference observed in $\left[{ }^{18} \mathrm{~F}\right]$ florbetapir uptake revealed in the discovery analysis, we performed a voxel-wise analysis. The analysis showed that carriers of $\mathrm{rs} 4388808^{\mathrm{G}}$ had less $\left[{ }^{18} \mathrm{~F}\right]$ florbetapir binding in the frontal, posterior cingulate, and inferior temporal cortices (figure 3), with the voxels in these regions presenting $p$ values equal to or less than 0.001 .

\section{Findings with brain imaging are corroborated by CSF data in the ADNI cohort}

Because of the well-known relationship between brain and CSF levels of $A \beta$, we tested the association between rs 4388808 and CSF A $\beta$. Because not all participants in the ADNI sample had CSF data, we performed the analysis in a subset of 260 individuals. As expected, MA carriers presented more CSF A $\beta$ than noncarriers $(t=2.94 ; p=0.003)$ (figure $2 \mathrm{~B})$. The CYP2C19 polymorphism was associated with the $\mathrm{A} \beta / \mathrm{p}$-tau ratio $(t=2.29$; $p=0.02)$, and higher ratios were found in carriers of $\mathrm{rs} 4388808^{\mathrm{G}}$ (figure 2C). No association was found using $\mathrm{p}$-tau as a single outcome measure $(t=-1.24 ; p=0.21)$.

\section{Association between the CYP2C19 polymorphism and $A \beta$ is exclusive to the $A \beta$ brain levels in the ADNI cohort}

To examine whether the CYP2C19 polymorphism is also associated with $A \beta$ levels outside the brain, we tested the 
Table 1 Demographic and key characteristics of the samples

\begin{tabular}{|c|c|c|c|c|c|c|}
\hline & \multicolumn{3}{|c|}{ ADNI } & \multicolumn{3}{|c|}{ Rush-ROS/MAP } \\
\hline & $\mathrm{CN}$ & $\mathrm{MCl}$ & $A D$ & $\mathrm{CN}$ & $\mathrm{MCl}$ & AD \\
\hline No. of participants & 186 & 105 & 47 & 301 & 179 & 258 \\
\hline Males, n (\%) & $91(48.9)$ & $64(61)$ & $26(55.3)$ & $182(60.5)$ & $101(56.4)$ & $154(59.7)$ \\
\hline Age, y, mean (SD) & $75.70(6.63)$ & $74.29(8.12)$ & $75.67(7.37)$ & $83.7(5.19)^{\mathrm{a} 3}$ & $85.26(4.35)$ & $85.95(3.81)$ \\
\hline APOE- $\varepsilon 4(\%)$ & $52(28)^{\mathrm{a} 1}$ & $57(54.3)^{\mathrm{a} 1}$ & $30(63.8)^{\mathrm{a} 1}$ & $49(16.4)^{\mathrm{a} 4}$ & $50(27.9)^{\mathrm{a} 4}$ & $112(43.4)^{\mathrm{a} 4}$ \\
\hline MMSE, mean (SD) & $29.09(1.14)^{\mathrm{a} 2}$ & $27.24(1.95)^{a 2}$ & $20.34(3.66)^{\mathrm{a} 2}$ & $28.69(1.42)^{\mathrm{a} 5}$ & $27.91(1.83)^{a 5}$ & $25.49(5.17)^{a \mathrm{a}}$ \\
\hline Education, y & $16.41(2.75)$ & $16.67(2.68)$ & $16.13(2.47)$ & $16.53(3.74)$ & $16.34(3.47)$ & $16.66(3.94)$ \\
\hline MA, n (\%) & $67(19)$ & $36(10)$ & $17(5)$ & $87(11)$ & $52(7)$ & $63(8.5)$ \\
\hline
\end{tabular}

Abbreviations: $A D=$ Alzheimer disease; $A D N I=A D$ Neuroimaging Initiative; $C N=$ cognitively normal; $M A=$ minor allele; $M A P=$ Memory and Aging Project; $\mathrm{MCl}=$ mild cognitive impairment; MMSE = Mini-Mental State Examination; ROS = Religious Orders Study.

a Statistically different from the other groups of the same sample; ${ }^{1} p=2.3 \times 10^{-7},{ }^{2} p=2 \times 10^{-16},{ }^{3} p=9.2 \times 10^{-8},{ }^{4} p=1.7 \times 10^{-11}$, and ${ }^{5} p=2 \times 10^{-16}$.

${ }^{\mathrm{b}} \mathrm{MA}\left(\mathrm{rs} 4388808^{\mathrm{G}}\right.$ ) percentage relative to its major sample (ADNI or Rush-ROS/MAP).

association of rs4388808 with plasmatic levels of $A \beta$ in a subsample of 113 participants. We did not find an association between the SNP and free $(t=-0.60 ; p=0.54)$ or total $(t=0.49 ; p=0.62)$ plasmatic $\mathrm{A} \beta_{1-42}$ levels (figure $2 \mathrm{D}$ ), indicating that the findings reported above are specific to the CNS.

\section{Results from the ADNI cohort were generalized to the Rush-ROS/MAP cohort}

We next generalized the findings to postmortem indices of the $A \beta$ load and to neurofibrillary tangles in Rush-ROS/MAP cohorts. From the 8 brain regions where the $A \beta$ load was measured, we selected 6 regions (angular gyrus, anterior cingulate, entorhinal cortex, and mesial and inferior temporal cortices) and calculated an average per subject. These 6 regions were chosen to match with the brain areas where we detected differences between genotype groups in the voxel-wise analysis. When testing the association between the average of the $A \beta$ load and the CYP2C19 polymorphism, we found that rs $4388808^{\mathrm{G}}(\mathrm{MAF}=0.15)$ carriers had a lower $\mathrm{A} \beta$ load than noncarriers $(t=-2.15 ; p=0.03)$ (figure $2 \mathrm{E}$ ), consistent with findings from the ADNI cohort. The difference between rs $4388808^{\mathrm{G}}$ carriers and noncarriers in PHF tau tangle density did not reach statistical significance $(t=-1.65 ; p=0.09)$.

\section{MA carriers of the CYP2C19 polymorphism had better cognitive performance than noncarriers in both cohorts}

To examine whether the CYP2C19 polymorphism affects the cognitive performance, we used composite measures of global cognition as the outcome in linear regression models. In the $\mathrm{ADNI}$ cohort, there was a clear tendency to an association with the CYP2C19 polymorphism $(t=1.92 ; p=0.05)$ (figure $2 \mathrm{~F}$ ), while in Rush-ROS/MAP cohorts, the association was such that $\mathrm{rs} 4388808^{\mathrm{G}}$ carriers had a higher cognition than noncarriers $(t=2.08 ; p=0.03)$ (figure $2 \mathrm{G}$ ).

\section{The effect of the CYP2C19 polymorphism on cognition is mediated by $A \beta$}

A mediation analysis was used to determine whether the CYP2C19 polymorphism was directly or indirectly associated with cognitive performance. We retested the association between the CYP2C19 polymorphism and cognition, but now adding the measures of $\left[{ }^{18} \mathrm{~F}\right]$ florbetapir or $A \beta$ load in the model. Neither of the previous genotype-phenotype associations remained significant, indicating that the observed effect of the genotype was mediated by $A \beta$.

\section{Association between rs4388808 and gene expression of CYP2C19 suggests that the SNP is functional}

To check whether the polymorphism has an effect in the gene expression, we tested the association between rs4388808 and CYP2C19 RNA levels. In the ADNI cohort, with 304 participants for this analysis, we found a cis eQTL such that MA carriers displayed higher RNA levels in the blood $(t=2.38$; $p=$ 0.01 ) (figure $2 \mathrm{H}$ ). In Rush-ROS/MAP cohorts, very low levels of CYP2C19 expression were detected in postmortem brains, and the data did not provide consistent results (data not shown) as found in the blood expression data from the ADNI.

\section{Discussion}

In the present study, we found an association between the CYP2C19 polymorphism and $A \beta$ burden across the spectrum

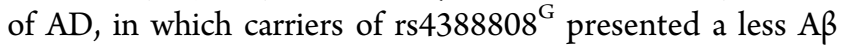
load and downstream cognitive impairment. This association was initially detected using the $\left[{ }^{18} \mathrm{~F}\right]$ florbetapir SUVR and posteriorly confirmed with CSF $A \beta$ in the ADNI cohort. No association was found between the polymorphism and diagnostic groups, suggesting that the SNP is associated with an amyloid load rather than with the disease status. Effect size 

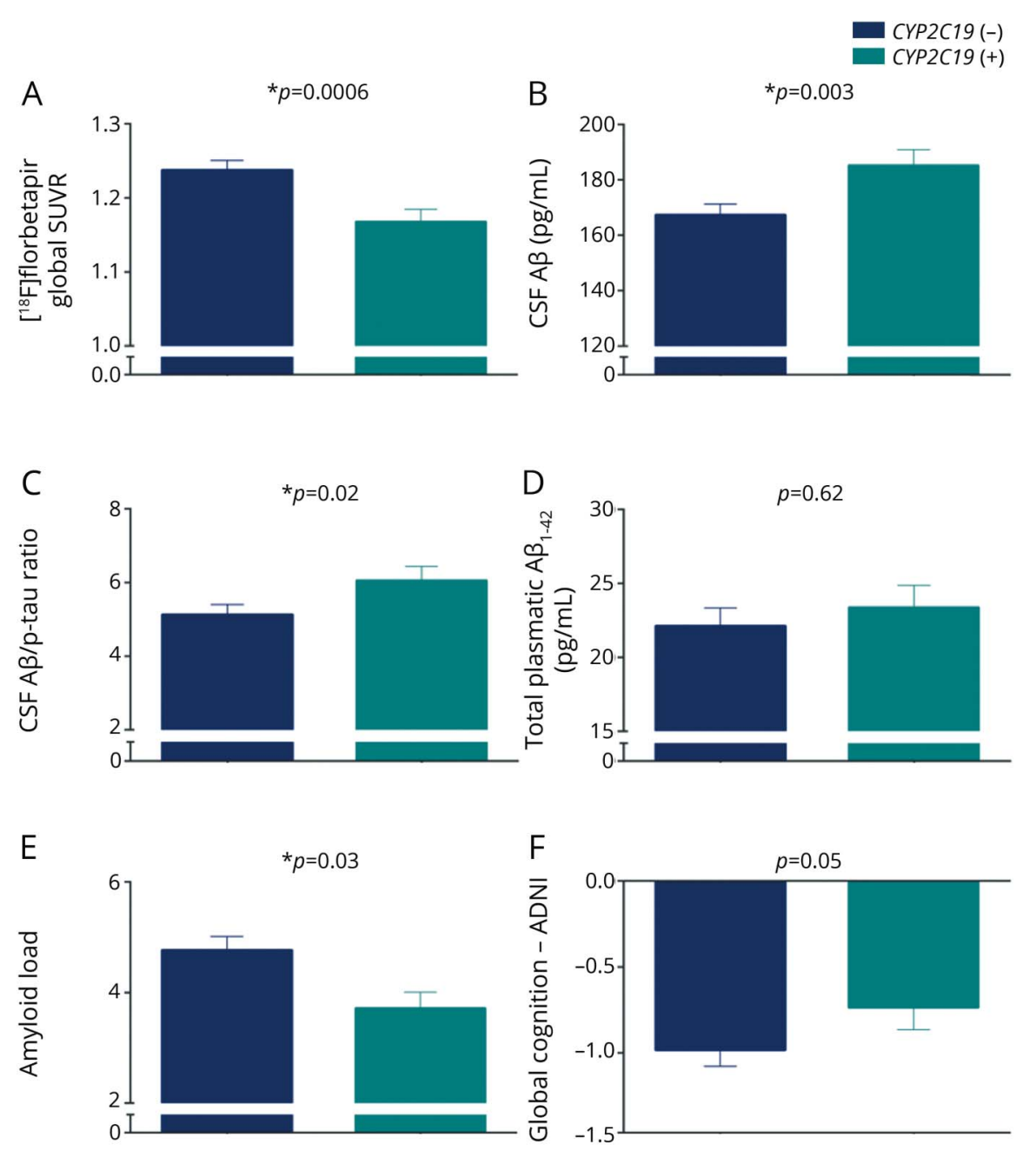

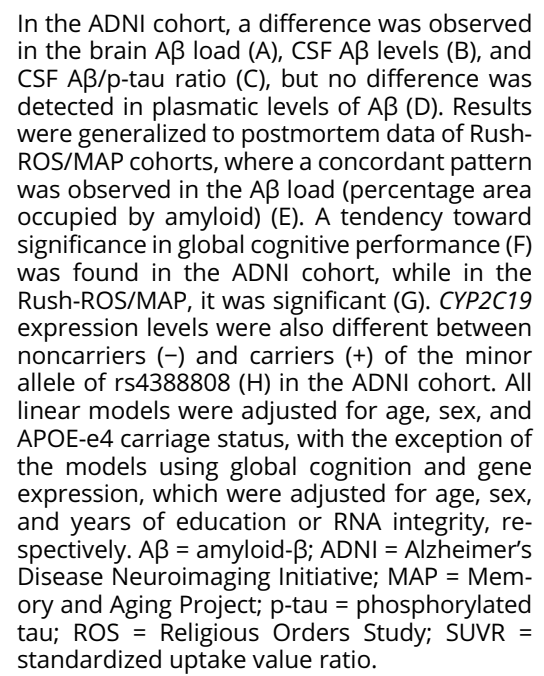
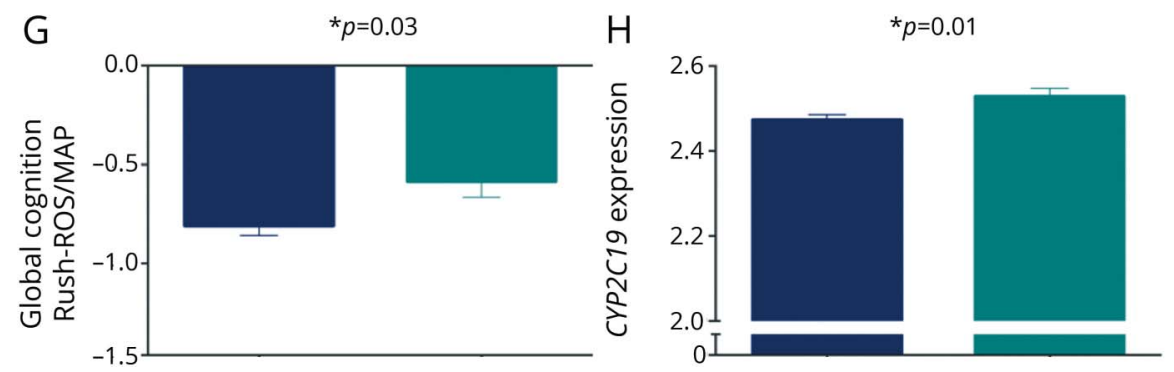

analysis suggests that the benefic effects of the polymorphism are larger in $A P O E-\varepsilon 4$ carriers, as compared to noncarriers or the whole sample, in which the effect is similar to what has been described for a BCHE gene polymorphism. ${ }^{22}$ Subsequently, this association was generalized to postmortem data from the Rush-ROS/MAP cohort. Finally, both cohorts showed a protective association between the MA of CYP2C19 and cognition. It is important that subsequent mediation analysis suggested that the effects of CYP2C19 on cognition were mediated by $\mathrm{A} \beta$.
Overall, these results support the notion that the MA of CYP2C19 (rs4388808) is a protective variant against $A \beta$ and downstream cognitive impairment. Of interest, voxel-wise analysis in in vivo participants revealed that the MA was associated with reduced $A \beta$ burden in $A D$-related regions in the frontal, inferior temporal, and posterior cingulate cortices. ${ }^{23}$ In addition, the CYP2C19 SNP was associated with the CSF $\mathrm{A} \beta / \mathrm{p}$-tau ratio but not with plasmatic $\mathrm{A} \beta$. Beyond the fact that the $A \beta / p$-tau ratio is postulated to better represent neuritic plaques than the single CSF $A \beta$ information, ${ }^{24}$ these results 
Figure 3 T-statistical parametric maps showing differences between noncarriers $(-)$ and carriers $(+)$ of the minor allele of rs4388808 (CYP2C19)

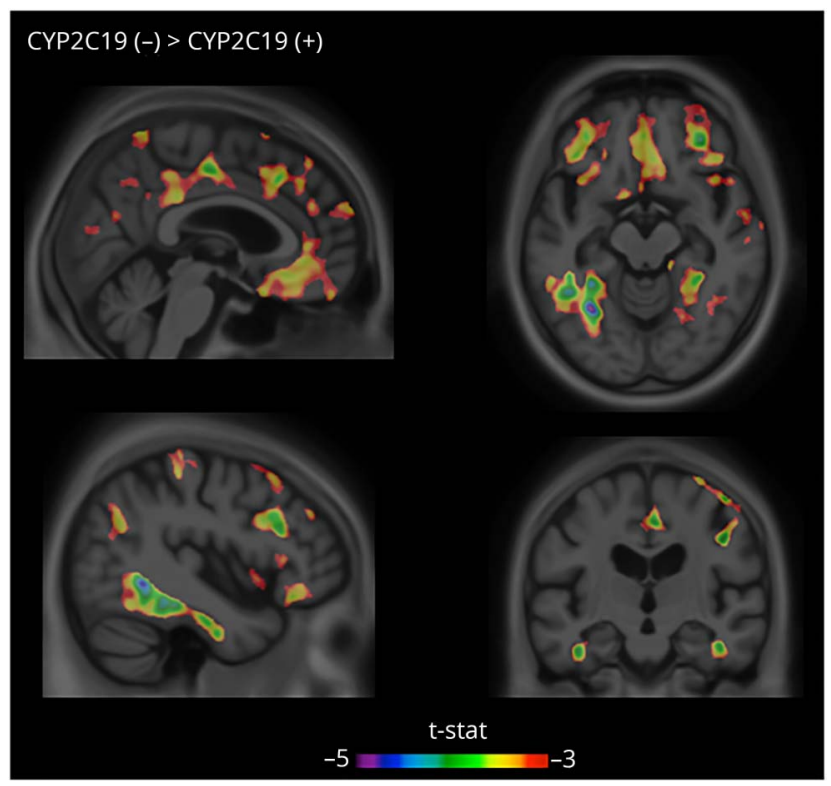

T-statistical parametric maps superimposed on average structural MRI show brain regions with lower standardized uptake value ratio (SUVR) values in minor allele carriers (CYP2C19 (+)) of the polymorphism of CYP2C19. Statistical differences overlap with brain regions vulnerable to Alzheimer disease pathophysiology, such as the posterior cingulate, frontal, and temporal cortices.

provide further evidence that the polymorphism affects the brain accumulation of neuritic plaques in a tissue- and diseasespecific manner. ${ }^{24}$ In both cohorts, the referred polymorphism was not associated with PHF tau or single CSF p-tau, agreeing with the framework that $A \beta$ and tau have independent upstream triggers. ${ }^{25}$ In line with overall significant results, the CYP2C19 polymorphism also presented a protective effect in global cognition, being supported by previous studies that linked $A \beta$ pathology to cognitive changes. ${ }^{13}$ Indeed, the mediation analysis supported that the association between the genetic factor and cognitive abnormalities is likely due to the upstream accumulation of $A \beta$.

Levels of the CYP2C19 protein are associated with the rs4388808 polymorphism, ${ }^{26}$ which is an intronic variant of the CYP2C19 gene. Indeed, we found a similar association showing that MA carriers expressed higher levels of CYP2C19 when compared with noncarriers, suggesting that the SNP affects the expression of its gene. To corroborate this finding, we retrieved the SNPs that were previously excluded because of high LD and verified that none was associated with CYP2C19 expression in the blood (data not shown), reinforcing the idea that rs4388808 is functional. This association could not be detected in postmortem data probably because of the low CYP expression or because of its limited detection by the method used. ${ }^{7}$

Despite the SNP not being widely studied to provide information about the association with other phenotypes, other polymorphisms in the gene have been correlated with metabolic variability, atherosclerosis, and behavioral traits. ${ }^{27-29}$ CYP2C19 expression has been detected in several brain regions ${ }^{6,7}$; however, its function in the CNS has not been fully elucidated. Some reports have suggested that, besides its role at metabolizing exogenous substrates, CYP2C19 also participates in other important biological cascades, such as the metabolism of serotonin and sexual hormones ${ }^{1}$ and the metabolism of the arachidonic acid (AA), where it functions as an epoxygenase. ${ }^{30}$

The biochemical mechanism underlying the association of CYP2C19 with $A \beta$ remains speculative. A study has shown that $\mathrm{A} \beta$ is able to act as a foreign body and trigger POR, activating CYPs to initiate catabolic reactions. ${ }^{9}$ In turn, CYP2C19 is involved in the catalysis of estradiol. ${ }^{31}$ Because several studies have reported the beneficial effects of estrogens on $\mathrm{AD}$-demonstrating that these steroids are able to act as anti-inflammatory compounds ${ }^{32}$ and even inhibit $A \beta$ production $^{33}$ - one could think that MA carriers of rs4388808 have a reduced expression of this CYP in the brain or that they have an increased structural incompatibility between CYP2C19 and estradiol. Consequently, MA carriers could present a reduction in the catabolism of estrogen and a reduction in the $A \beta$ load. Alternatively, the $A \beta$ load would be affected by the levels of epoxyeicosatrienoic acids (EETs) produced via the metabolism of AA by CYP epoxygenases. In the brain, studies have shown that EETs have beneficial effects at regulating blood flow, cortical angiogenesis, and at promoting anti-inflammatory reactions (for review, see reference 2 ). By contrast, when AA is metabolized via other cascades, the protective effect of EETs is lost, and there is a possibility of induction of $A \beta$ production and/or accumulation. ${ }^{34}$ In addition, it was demonstrated that $A \beta$ is able to reduce epoxygenase activity and consequently decrease EET production, ${ }^{35}$ probably leading to more susceptibility to neuronal damage (for review, see reference 36). In this scenario, it would be possible that the MA of rs4388808 increases the expression of CYP2C19, leading to an "A $\beta$-resistant" epoxygenase metabolism of $\mathrm{AA}$, with a maintained production of EETs and a more protective phenotype against amyloidosis.

It is also plausible to think, however, that the association described here between the CYP2C19 polymorphism and A $\beta$ is indirect, being mediated by the effect of a drug. CYP2C19 is known to metabolize several drugs, ${ }^{37}$ including medications to treat depression, which has been mentioned as a risk factor for $\mathrm{AD}$ (for review, see reference 38). Citalopram, for example, is an antidepressant metabolized by CYP2C19 that has been shown to decrease $\mathrm{A} \beta$ production. ${ }^{39}$ Thus, one may think that the polymorphism rs4388808 is then associated with an improved action of citalopram, leading to the decreased brain $A \beta$ burden, rather than associated with $A \beta$ metabolism itself. Because it is difficult to track all the medications the study participants have taken before been enrolled, it is unfeasible at the moment to check whether this association holds true. 
The interpretation of the results should take into consideration a few limitations. The use of the 2 cohorts does not allow us to detect and measure $A \beta$ pathology with the same methodology, inserting in the analysis some variability specific to the method used. However, despite being measured with different techniques, both the imaging radiotracer and the antibody used in the brain tissue are expected to bind to the fibrillar form of $\mathrm{A} \beta{ }^{13}$ Similarly, the cognitive composite scores from the 2 cohorts have some differences that should be considered. There are also some intrinsic characteristics of the samples that have to be taken into account: (1) the inclusion criteria of each study, (2) the average age difference between the studies, and (3) and the disease stage in which $A \beta$ measures were performed - at the end or during the disease process. Sample size restrictions impose some degree of caution when interpreting findings, including, for example, the lack of association between the genotype and plasmatic levels of $A \beta$, or cognition, in the ADNI cohort. In addition, both cohorts are mostly composed of non-Latino Caucasians, limiting the extrapolation of the present findings to other population groups. Longitudinal analysis together with functional genomics and biochemistry experiments, not performed here, would also be necessary to determine the effect of the SNP in the protein function as well as to support any theoretical framework proposed in the Discussion section.

Results obtained from the 2 independent cohorts provide compelling evidences linking the CYP2C19 polymorphism and $A \beta$ pathology, suggesting that the MA of rs 4388808 confers protective effects against $A \beta$ accumulation in the brain and its downstream cognitive consequences. These results could have implication for antiamyloid clinical trial designs, as preclinical rs $4388808^{\mathrm{G}}$ would present a protective factor against the amyloid load. Therefore, the biological mechanism by which the genetic variation would alter $A \beta$ build up and clearance merits further investigation.

\section{Author contributions}

Andréa L. Benedet: study concept, design, analysis and interpretation of data, composition of figures, and drafting the manuscript.

Lei Yu: analysis and interpretation of data and drafting the manuscript. Aurélie Labbe: supervision of statistical analysis and critical review of the manuscript for intellectual content. Sulantha Mathotaarachchi, Tharick A. Pascoal, Monica Shin, and Min-Su Kang: processing of image data and drafting the manuscript, study concept, design, and drafting the manuscript. Serge Gauthier, Guy A. Rouleau, and Judes Poirier: critical review of the manuscript for intellectual content. David A. Bennett: drafting the manuscript and critical review of the manuscript for intellectual content. Pedro Rosa-Neto: study concept, design, study supervision, and critical review of the manuscript for intellectual content.

\section{Acknowledgment}

Data collection and sharing for this project was funded by the Alzheimer's Disease Neuroimaging Initiative (ADNI) (NIH grant U01 AG024904) and the DOD ADNI (Department of Defense award number W81XWH-12-2-0012). The ADNI is funded by the National Institute on Aging, the National Institute of Biomedical Imaging and Bioengineering, and through generous contributions from the following: AbbVie, the Alzheimer's Association; the Alzheimer's Drug Discovery Foundation; Araclon Biotech; BioClinica, Inc.; Biogen; Bristol-Myers Squibb; CereSpir, Inc.; Cogstate; Eisai Inc.; Elan Pharmaceuticals, Inc.; Eli Lilly and Company; Euroimmun; F. Hoffmann-La Roche Ltd and its affiliated company Genentech, Inc.; Fujirebio; GE Healthcare; IXICO Ltd.; Janssen Alzheimer Immunotherapy Research \& Development, LLC.; Johnson \& Johnson Pharmaceutical Research \& Development LLC.; Lumosity; Lundbeck; Merck \& Co., Inc.; Meso Scale Diagnostics, LLC.; NeuroRx Research; Neurotrack Technologies; Novartis Pharmaceuticals Corporation; Pfizer Inc.; Piramal Imaging; Servier; Takeda Pharmaceutical Company; and Transition Therapeutics. The Canadian Institutes of Health Research is providing funds to support ADNI clinical sites in Canada. Private sector contributions are facilitated by the Foundation for the NIH (fnih.org). The grantee organization is the Northern California Institute for Research and Education, and the study is coordinated by the Alzheimer's Therapeutic Research Institute at the University of Southern California. ADNI data are disseminated by the Laboratory for Neuro Imaging at the University of Southern California.

\section{Study funding}

This work was also supported by the Canadian Institutes of Health Research (CIHR) (MOP-11-51-31), the Alzheimer's Association (NIRG-08-92,090), the Canadian Consortium on Neurodegeneration in Aging (CIHR-CCNA), and the Weston Brain Institute. Andréa L. Benedet is supported by the CAPES Foundation-Brazil (0327/13-1). Pedro RosaNeto is supported by the Fonds de la recherche en santé du Québec (chercheur boursier). Serge Gauthier and Pedro Rosa-Neto are members of the CIHR Canadian Consortium on Neurodegeneration in Aging. The Religious Orders Study and the Rush Memory and Aging Project are funded by the National Institute on Aging (P30AG10161 and R01AG17917) and the Illinois Department of Public Health.

\section{Disclosure}

A.L. Benedet has received research support from the CAPES Foundation. L. Yu has received research support from the NIH. A. Labbe and S. Mathotaarachchi report no disclosures. T.A. Pascoal has received research support from the PREVENT-AD PhD scholarship. M. Shin and M.-S. Kang report no disclosures. S. Gauthier has received honoraria for serving on the scientific advisory boards of Alzheon, Axovant, Boehringer Ingelheim, Lilly, Lundbeck, Novartis, Schwabe, TauRx, on the DSMB of a study sponsored by Eisai, and for studies run by the ADCS and by the ATRI; has received speaker honoraria from Schwabe; serves on the editorial board of Alzheimer's \& Dementia; has served as a consultant for Kalgene; and has received research support from the CIHR, the NIH, Lundbeck, Roche, and Lilly. G.A. Rouleau has 
received research support from the CIHR, the ALS Society of Canada, and the ALS Association. J. Poirier serves on the editorial board of the Journal of Alzheimer's Disease; receives publishing royalties from Trécarré; and has received research support from the J.L. Levesque Foundation. D.A. Bennett serves on the scientific advisory boards of Vigorous Minds, Takeda Pharmaceuticals, AbbVie, EABs (Indian Institute of Science), DMCs (HRS and MIDUS), and the National Advisory Council on Aging; is a consultant for Takeda Pharmaceuticals and AbbVie; has received research support from the NIH; and serves on the editorial boards of Neurology, Current Alzheimer Research, and Neuroepidemiology. P. RosaNeto serves on the scientific advisory boards of Enigma Radiopharmaceuticals and Kalgene; serves on the editorial board of Frontiers in Aging Neurosciences; and has received research support from Enigma Radiopharmaceuticals, Eli Lilly, the CIHR, the FRQS, Merck (Sharp \& Dohme Corporation/ McGill Faculty of Medicine Grant for Translational Research), the Weston Brain Institute, the Alzheimer's Association, Brain Canada, and CQDM. Funding information and disclosures are provided at the end of the article. Full disclosure form information provided by the authors is available with the full text of this article at Neurology.org/NG.

Received June 8, 2017. Accepted in final form December 4, 2017.

\section{References}

1. Miksys S, Tyndale RF. Cytochrome P450-mediated drug metabolism in the brain. J Psychiatry Neurosci 2013;38:152-163.

2. Iliff JJ, Jia J, Nelson J, Goyagi T, Klaus J, Alkayed NJ. Epoxyeicosanoid signaling in CNS function and disease. Prostaglandins Other Lipid Mediat 2010;91:68-84.

3. Stingl JC, Brockmoller J, Viviani R. Genetic variability of drug-metabolizing enzymes: the dual impact on psychiatric therapy and regulation of brain function. Mol Psychiatry 2013;18:273-287.

4. McCann SJ, Pond SM, James KM, Le Couteur DG. The association between polymorphisms in the cytochrome P-450 2D6 gene and Parkinson's disease: a case-control study and meta-analysis. J Neurol Sci 1997;153:50-53.

5. Chace C, Pang D, Weng C, et al. Variants in CYP17 and CYP19 cytochrome P450 genes are associated with onset of Alzheimer's disease in women with down syndrome. JAlzheimer Dis 2012;28:601-612.

6. McFayden MC, Melvin WT, Murray GI. Regional distribution of individual forms of cytochrome P450 mRNA in normal adult human brain. Biochem Pharmacol 1998;55:825-830.

7. Booth Depaz IM, Toselli F, Wilce PA, Gillam EM. Differential expression of cytochrome P450 enzymes from the CYP2C subfamily in the human brain. Drug Metab Dispos 2015;43:353-357.

8. Van Ess PJ, Pedersen WA, Culmsee C, Mattson MP, Blouin RA. Elevated hepatic and depressed renal cytochrome P450 activity in the Tg2576 transgenic mouse model of Alzheimer's disease. J Neurochem 2002;80:571-578.

9. Pappolla MA, Omar RA, Chyan YJ, et al. Induction of NADPH cytochrome P450 reductase by the Alzheimer beta-protein: amyloid as a "foreign body." J Neurochem 2001;78:121-128.

10. Liu M, Sun A, Shin EJ, et al. Expression of microsomal epoxide hydrolase is elevated in Alzheimer's hippocampus and induced by exogenous beta-amyloid and trimethyl-tin. Eur J Neurosci 2006;23:2027-2034.

11. Bennett DA, Schneider JA, Arvanitakis Z, Wilson RS. Overview and findings from the religious orders study. Curr Alzheimer Res 2012;9:628-645.
12. Bennett DA, Schneider JA, Buchman AS, Barnes LL, Boyle PA, Wilson RS. Overview and findings from the rush Memory and Aging Project. Curr Alzheimer Res 2012;9: 646-663.

13. Bennett DA, Schneider JA, Wilson RS, Bienias JL, Arnold SE. Neurofibrillary tangles mediate the association of amyloid load with clinical Alzheimer disease and level of cognitive function. Arch Neurol 2004;61:378-384.

14. Saykin AJ, Shen L, Yao X, et al. Genetic studies of quantitative MCI and AD phenotypes in ADNI: Progress, opportunities, and plans. Alzheimers Dement 2015;11: 792-814.

15. Lim AS, Srivastava GP, Yu L, et al. 24-hour rhythms of DNA methylation and their relation with rhythms of RNA expression in the human dorsolateral prefrontal cortex. PLoS Genet 2014;10:e1004792.

16. Rogers JF, Nafziger AN, Bertino JS Jr. Pharmacogenetics affects dosing, efficacy, and toxicity of cytochrome P450-metabolized drugs. Am J Med 2002;113:746-750.

17. Anzenbacher P, Anzenbacherova E. Cytochromes P450 and metabolism of xenobiotics. Cell Mol Life Sci 2001;58:737-747.

18. Meyer RP, Gehlhaus M, Knoth R, Volk B. Expression and function of cytochrome p450 in brain drug metabolism. Curr Drug Metab 2007;8:297-306.

19. Purcell S, Neale B, Todd-Brown K, et al. PLINK: a tool set for whole-genome association and population-based linkage analyses. Am J Hum Genet 2007;81: 559-575.

20. R: A Language and Environment for Statistical Computing [computer program]. Version 3.1.0. Vienna: R Foundation for Statistical Computing; 2015.

21. Package RMINC: Voxel-Wise Morphometry Using RMINC [computer program]. Montreal: McGill University; 2010.

22. Ramanan VK, Risacher SL, Nho K, et al. APOE and BCHE as modulators of cerebral amyloid deposition: a florbetapir PET genome-wide association study. Mol Psychiatry 2014;19:351-357.

23. Braak H, Braak E. Neuropathological stageing of Alzheimer-related changes. Acta Neuropathol 1991;82:20.

24. Tapiola T, Alafuzoff I, Herukka S, et al. Cerebrospinal fluid $\beta$-amyloid 42 and tau proteins as biomarkers of Alzheimer-type pathologic changes in the brain. Arch Neurol 2009;66:382-389.

25. Sperling R, Mormino E, Johnson K. The evolution of preclinical Alzheimer's disease: implications for prevention trials. Neuron 2014;84:608-622.

26. Wang D, Jiang Z, Shen Z, et al. Functional evaluation of genetic and environmental regulators of p450 mRNA levels. PLoS One 2011;6:e24900.

27. Sim SC, Risinger C, Dahl ML, et al. A common novel CYP2C19 gene variant causes ultrarapid drug metabolism relevant for the drug response to proton pump inhibitors and antidepressants. Clin Pharmacol Ther 2006;79:103-113.

28. Ishii G, Suzuki A, Oshino S, Shiraishi H, Otani K. CYP2C19 polymorphism affects personality traits of Japanese females. Neurosci Lett 2007;411:77-80.

29. Ercan B, Ayaz L, Cicek D, Tamer L. Role of CYP2C9 and CYP2C19 polymorphisms in patients with atherosclerosis. Cell Biochem Funct 2008;26:309-313.

30. Westphal C, Konkel A, Schunck WH. CYP-eicosanoids-a new link between omega3 fatty acids and cardiac disease? Prostaglandins Other Lipid Mediat 2011;96: 99-108.

31. Cheng ZN, Shu Y, Liu ZQ, Wang LS, Ou-Yang DS, Zhou HH. Role of cytochrome P450 in estradiol metabolism in vitro. Acta Pharmacol Sin 2001;22:148-154.

32. Giraud SN, Caron CM, Pham-Dinh D, Kitabgi P, Nicot AB. Estradiol inhibits ongoing autoimmune neuroinflammation and NFkappaB-dependent CCL2 expression in reactive astrocytes. Proc Natl Acad Sci USA 2010;107:8416-8421.

33. Xu H, Wang R, Zhang YW, Zhang X. Estrogen, beta-amyloid metabolism/trafficking, and Alzheimer's disease. Ann NY Acad Sci 2006;1089:324-342.

34. Amtul Z, Uhrig M, Wang L, Rozmahel RF, Beyreuther K. Detrimental effects of arachidonic acid and its metabolites in cellular and mouse models of Alzheimer's disease: structural insight. Neurobiol Aging 2012;33:831.e21-e31.

35. Sarkar P, Narayanan J, Harder DR. Differential effect of amyloid beta on the cytochrome P450 epoxygenase activity in rat brain. Neuroscience 2011;194:241-249.

36. Kisler K, Nelson AR, Montagne A, Zlokovic BV. Cerebral blood flow regulation and neurovascular dysfunction in Alzheimer disease. Nat Rev Neurosci 2017;18:419-434.

37. Bibi Z. Role of cytochrome P450 in drug interactions. Nutr Metab (Lond) 2008;5:27.

38. Ownby RL, Crocco E, Acevedo A, John V, Loewenstein D. Depression and risk for Alzheimer disease: systematic review, meta-analysis, and metaregression analysis. Arch Gen Psychiatry 2006;63:530-538.

39. Sheline YI, West T, Yarasheski K, et al. An antidepressant decreases CSF Abeta production in healthy individuals and in transgenic AD mice. Sci Transl Med 2014;6: $236 \mathrm{re} 234$. 


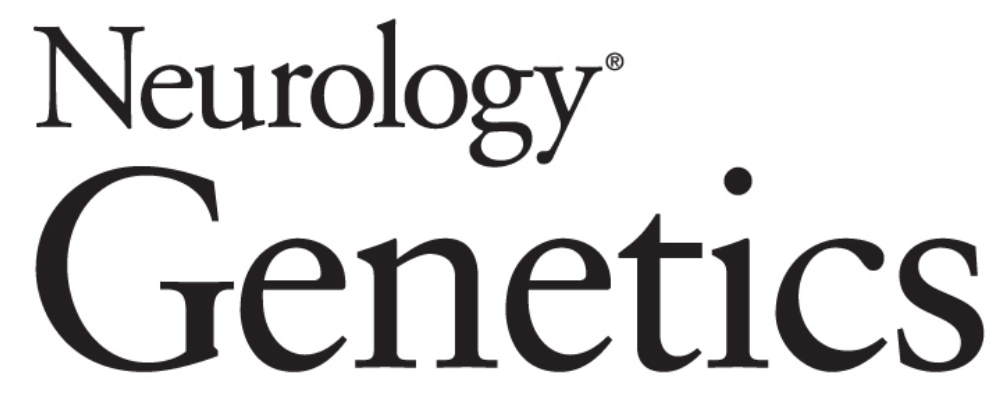

CYP2C19 variant mitigates Alzheimer disease pathophysiology in vivo and postmortem Andréa L. Benedet, Lei Yu, Aurélie Labbe, et al. Neurol Genet 2018;4;

DOI 10.1212/NXG.0000000000000216

This information is current as of January 30, 2018

\section{Updated Information \&} Services

\section{References}

Citations

Subspecialty Collections

Permissions \& Licensing

Reprints including high resolution figures, can be found at: http://ng.neurology.org/content/4/1/e216.full.html

This article cites 37 articles, 3 of which you can access for free at: http://ng.neurology.org/content/4/1/e216.full.html\#\#ref-list-1

This article has been cited by 1 HighWire-hosted articles: http://ng.neurology.org/content/4/1/e216.full.html\#\#otherarticles

This article, along with others on similar topics, appears in the following collection(s):

Alzheimer's disease

http://ng.neurology.org//cgi/collection/alzheimers_disease

Association studies in genetics

http://ng.neurology.org//cgi/collection/association_studies_in_genetics PET

http://ng.neurology.org//cgi/collection/pet

Information about reproducing this article in parts (figures,tables) or in its entirety can be found online at:

http://ng.neurology.org/misc/about.xhtml\#permissions

Information about ordering reprints can be found online: http://ng.neurology.org/misc/addir.xhtml\#reprintsus

Neurol Genet is an official journal of the American Academy of Neurology. Published since April 2015, it is an open-access, online-only, continuous publication journal. Copyright Copyright @ 2018 The Author(s). Published by Wolters Kluwer Health, Inc. on behalf of the American Academy of Neurology.. All rights reserved. Online ISSN: 2376-7839.

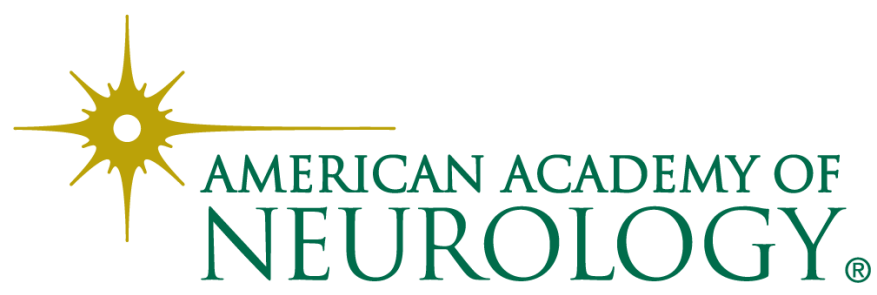

